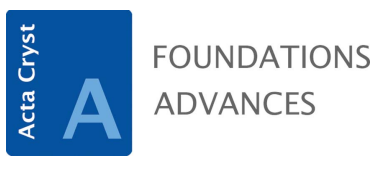

ISSN 2053-2733

\section{X-Ray Crystallography. Second Edition. By William Clegg. Oxford University Press, 2015. Pp. 128. Price GBP 14.99 (paperback). ISBN 9780198700975.}

School of Chemistry, University of Manchester, Manchester M13 9PL, UK. *Correspondence e-mail: john.helliwell@manchester.ac.uk
Keywords: book review; X-ray crystallography.

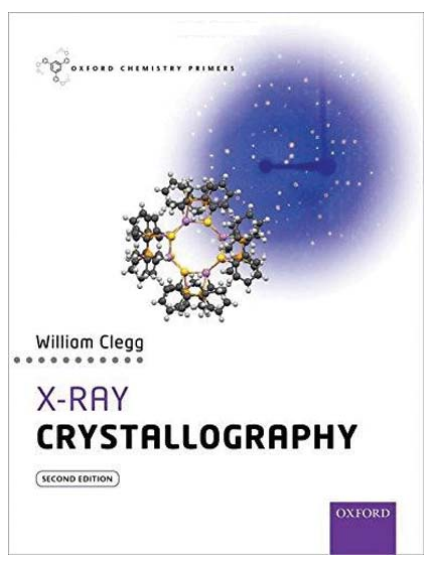

(C) 2017 International Union of Crystallography
During my career, I have taught undergraduates majoring in physics and undergraduates majoring in chemistry. I have also taught molecular biologists and biochemists. My initial preference in teaching X-ray crystallography to any undergraduate was for my physics undergraduate course book in crystallography by Michael Woolfson (1970). However, that book, with its clear mathematical foundation, is too mathematical for teaching chemists or biologists. At one point I considered writing my own textbook for teaching and went so far as to making a book proposal to Oxford University Press (OUP) for a book within its Primer series. The breadth of scope that I proposed, encompassing 'small molecule' as well as 'large molecule' crystallography, was considered to be too wide for the approximately 100-page limit within the Primer series budget (a teaching textbook needs to be 'affordable' by undergraduates). In any case, my core inorganic chemistry course needed to cover 'small molecule' crystallography, and the 'large molecule' crystallography needed to be in a separate third-year chemistry option course, the most stable form of which I found was within the topic of 'bioinorganic chemistry'. Now, however, a very wide overview of all of crystallography in 100 pages is splendidly encompassed by Mike Glazer's recent book Crystallography - a Very Short Introduction, also published by OUP (Glazer, 2016). There is also of course the superb book covering biological and chemical crystallography by Jenny Glusker et al. (1994).

Fortunately, the first edition of William (Bill) Clegg's book $X$-ray Crystallography in the Oxford Primer Series came along at a propitious stage of my teaching career and was a masterpiece of experience in chemical crystallography and clear description. Bill Clegg's first edition was excellent and great value for money, and so became the mainstay of my recommendations to undergraduates in their core inorganic chemistry courses for many years. Now here is the second edition.

It is an honour to be asked to review such a successful teaching book. So, what are the author's aims for this second edition? The Preface and the back cover make it clear that the aims were to update the descriptions of the technology and procedures that are used to obtain good and properly validated crystal structures. I have read the book and tried the e-learning centre exercises. The text, as well as the exercises, have also been 'supplemented by accounts of biological macromolecular crystallography and of crystal structure prediction'. There is a section of the e-learning resource centre for lecturers; I tried to register for this but it requires prior vetting by an OUP sales representative, which is fair enough. In any case, a lecturer is likely to want to use their own case studies. For example, I would try to use some of (i.e. varying my choice each year) the historical crystal-structure-analysis classics of W. L. Bragg, Kathleen Lonsdale, Dorothy Hodgkin and Max Perutz, namely: the comparison of the diffraction patterns of $\mathrm{NaCl}$ and $\mathrm{KCl}$, the study of hexachlorobenzene, the $\beta$-lactam ring in penicillin (the induced by the X-rays or not' story), vitamin B12, and the movement of the iron atom in haemoglobin on oxygenation leading to cooperativity between protein subunits ('the flea that made the elephant jump', as Max Perutz vividly described it). If possible I would also introduce the beautifully elegant reflection phasing via two X-ray wavelengths and three measurements, namely involving an anomalous difference and a dispersive difference (Helliwell, 1984, Fig. 52), and maybe a case study on metal-atom location and identification, made exquisitely sensitive using tuneable synchrotron radiation X-rays. 
I read the whole of the second edition of this book avidly. It is easy to read, and I didn't find a single typographical error. The tiniest of quibbles is that I found that the typography of the Contents page rather poor: while the chapter titles are in bold, the subtitles are in an almost invisible (to my age of eyes) grey; OUP could improve this. The recommended supplementary books include one that I know very well: David Blow's excellent Outline of Crystallography for Biologists (Blow, 2002), and several other very fine texts are recommended for further reading.

In conclusion, I highly recommend this book to lecturers describing the topic of X-ray crystallography to undergraduate 'core inorganic' chemists as well as to the students themselves taking such a course, who should also rightly consider it a bargain at the price.

\section{References}

Blow, D. M. (2002). Outline of Crystallography for Biologists. Oxford University Press.

Glazer, A. M. (2016). Crystallography - a Very Short Introduction. Oxford University Press.

Glusker, J. P., Lewis, M. \& Rossi, M. (1994). Crystal Structure Analysis for Chemists and Biologists. Wiley.

Helliwell, J. R. (1984). Rep. Prog. Phys. 47, 1403-1497.

Woolfson, M. M. (1970). An Introduction to X-ray Crystallography (2nd edition 1997). Cambridge University Press. 